\title{
Near-Field Variability of Residential Woodsmoke Concentrations
}

\author{
Tracy L. Thatcher ${ }^{*}$, Thomas W. Kirchstetter ${ }^{2}$, Stella H. Tan', \\ Christopher J. Malejan'1, Courtney E. Ward ${ }^{1}$ \\ ${ }^{1}$ Environmental Engineering, California Polytechnic State University, San Luis Obispo, USA \\ ${ }^{2}$ Environmental Energy Technologies Division, Lawrence Berkeley National Laboratory, Berkeley, USA \\ Email: ${ }^{*}$ thatche@calpoly.edu
}

Received 12 July 2014; revised 15 August 2014; accepted 10 September 2014

Copyright (C) 2014 by authors and Scientific Research Publishing Inc.

This work is licensed under the Creative Commons Attribution International License (CC BY). http://creativecommons.org/licenses/by/4.0/

(c) (i) Open Access

\begin{abstract}
In many regions, wood combustion is a significant source of wintertime aerosols. However, since wood combustion sources are interspersed within neighborhoods, near-field concentration variability has the potential to cause large variations in the exposure levels between residents over a relatively small area. This field study compared filter samples and aethalometer measurements of black carbon concentration within a $1 \mathrm{~km}^{2}$ study region with no significant aerosol sources except wood combustion. Sampling occurred on 15 nights over two winter seasons in a small California coastal town. Even over the small distances in the study area, large spatial and temporal variations were observed. Measured black carbon concentrations varied by as much as a factor of 10 over a 12-hour night-time period. The spatial variability was non-random, with the highest location in the study area experiencing 4 times the average concentration within the neighborhood, when averaged over all sample periods. The results of this study indicate that within neighborhoods with residential wood combustion sources using an average concentration for a region to predict exposure may significantly undervalue the exposure of some residents and overvalue the exposure for others.
\end{abstract}

\section{Keywords}

Spatial Variability, Temporal Variability, Woodsmoke, Black Carbon (BC)

\section{Introduction}

Most efforts to characterize and control ambient air pollution have focused on sources that degrade air quality

\footnotetext{
"Corresponding author.
}

How to cite this paper: Thatcher, T.L., Kirchstetter, T.W., Tan, S.H., Malejan, C.J. and Ward, C.E. (2014) Near-Field Variability of Residential Woodsmoke Concentrations. Atmospheric and Climate Sciences, 4, 622-635. 
over large portions of an air basin, creating a relatively similar concentration within regions of the air basin. Consistent with this objective, most ambient air quality monitoring stations are deliberately sited to avoid influences of local emission sources. This creates a gap in our understanding of exposures near outdoor pollutant sources. Although zoning regulations tend to group industrial sources away from residential areas, generation can occur within residential neighborhoods. This is especially true for residential wood smoke which is widely recognized as a major contributor to wintertime $\mathrm{PM}_{2.5}$ concentrations in many areas. Residential wood combustion is typically considered as an "area" source, since the wide distribution of small sources can be well characterized as an area source when concentrations are viewed at a regional scale. However, when viewed on the scale of individuals within a neighborhood, these sources may have significantly variable impacts based on the location of the person relative to each source. Being able to quantify the importance of the near-field exposure component to overall exposures is critical for understanding the relative exposure to wood smoke emissions. When attempting to determine the health risks associated with wood smoke emissions, the following two questions arise: (1) Is monitoring station data a reasonable proxy for the average wood-smoke concentrations to which people are exposed? (2) How much does the exposure vary for individuals within the same community based on their location within the source field? The answers to these questions depend on the characteristics and variability of the near-field concentrations within an "area source" of residential wood burning.

A large number of studies have investigated spatial variability in PM from vehicular or unspecified sources. Many of these studies evaluated PM variability within urban scales, defined as $4 \mathrm{~km}$ through $100 \mathrm{~km}$ in diameter, length, or width, and neighborhood scales, defined as $500 \mathrm{~m}$ to $4 \mathrm{~km}$ in diameter, length, or width (40 CFR part 58). While some researchers have found fairly consistent concentrations within urban scales [1] [2], other studies have found significant concentration differences on the smaller neighborhood scale. Higher variability in PM has been shown to occur in the presence of numerous gasoline and diesel vehicles, while variability declines when only background PM levels are observed [3]. Gulliver and Briggs [4] found large standard deviations when measuring $\mathrm{PM}_{10}, \mathrm{PM}_{2.5}$, and $\mathrm{PM}_{1}$ concentrations at 1 second resolution over two routes comprising high traffic and low traffic areas while walking and driving. Both the walking and driving routes yielded standard deviations in concentration that were approximately equal to the average concentrations. Due to the nature of the study designs, these standard deviations combine both spatial and temporal variability in concentration.

Although the phenomenon of higher near-field exposures has been well documented for traffic sources, wood smoke from residential combustion is a pollutant source that differs significantly from most other sources. With wood smoke, the receptors of interest (people in their homes) are interspersed within a field of small stationary sources. Residential wood burning occurs mostly at night and in the winter, periods when atmospheric mixing can be suppressed by low inversions and stagnant conditions. The variability in heat output and therefore plume rise from the individual sources will cause residential wood smoke plumes to disperse differently depending on the source characteristics. Both Gorin et al. [1] and Glasius, et al. [5] found elevated wood smoke concentrations in samples taken in residential areas. However, neither study provided the spatial resolution needed to determine the variation of concentrations within those residential areas.

Robinson et al. [6] found large differences in $\mathrm{PM}_{2.5}$ concentration averages over a distance of only 41 meters (35 $\mu \mathrm{g} / \mathrm{m}^{3}$ and $90 \mu \mathrm{g} / \mathrm{m}^{3}$ ) when sampling with a mobile nephelometer and higher concentrations were found in areas where wood burning was prevalent. Smargiassi et al. [7] performed mobile sampling for $\mathrm{PM}_{1}$ over 10 routes in residential regions of Quebec. They report that their data suggests that the impact of wood burning on $\mathrm{PM}_{1}$ emissions varies on a small geographic scale. Wang et al. compared a single fixed site monitoring location to 12 minute samples collected by a mobile sampling system located sequentially at 12 different sampling locations over approximately $8 \mathrm{~km}$. They found that wintertime residential wood smoke concentrations exhibited high spatial heterogeneity within the study area. While mobile sampling can demonstrate differences in concentrations over short distances, changes to concentrations over time remain unaccounted for.

Some studies evaluating wood smoke contributions to PM concentrations in small areas have only measured temporal variability at one location and have had to differentiate between PM contributors. One study evaluated both coal and wood burning contributions to winter $\mathrm{PM}_{10}$ and black smoke in the Czech Republic within a small rural village [8] and found that concentrations varied by more than a factor of 10. A strong correlation between black smoke and $\mathrm{PM}_{10}$ concentrations indicated that the main source of $\mathrm{PM}_{10}$ was likely household combustion processes.

Allen, et al. [9] combined mobile sampling with measurements at six fixed sites to investigate both spatial and temporal variability across an area spanning approximately 50 miles. They found high spatial and temporal variability with the averages between fixed sites varying by a factor of about 6 and mobile monitoring showing 
large spikes which occurred for short time periods with the highest spike being over 7 times higher than the largest 3-hour average. Larson, et al. [10] also combined fixed measurements (2-week filter samples) with mobile monitoring data for measurements in Vancouver, B.C. over a region approximately $40 \mathrm{~km}$ long. They report large differences in concentration over relatively small distances, with many instances of measurements of concentrations in the "bottom third" adjacent to locations in the "top third".

Although researchers have identified significant spatial variability for residential wood smoke concentrations on the urban scale, there is limited data about the variability within neighborhoods. This study provides a unique data set for assessing near-field wood smoke concentration variability within a neighborhood and assessing the potential impact these variations have on our understanding of human exposures to wood smoke particles.

\section{Experimental Methods}

To investigate near-field variability, outdoor sampling was performed within a 1 square kilometer residential area encompassing approximately 400 homes. The basic method for field sampling events, referred to as Intensive Operation Periods (IOPs), was as follows: (1) all equipment to be used was checked, programmed and calibrated as needed, (2) filter samplers and aethalometers were placed at locations within the $1 \mathrm{~km}^{2}$ study area to sample for a 12-hour period overnight, (3) after sampling started the study area was surveyed using an infrared camera to determine which homes were actively using their chimneys, (4) samplers were collected the following morning.

The site selected for the study was in Cambria, California. The town spans about $3 \mathrm{~km}^{2}$, is populated by approximately 6500 people, and lists tourism, light industry, and agriculture as its main industrial activities [11]. Cambria is located on the central coast of California (35.554030, -121.087394) with elevations ranging from sea level to 250 feet. It is bordered to the west by the Pacific Ocean and to the east by the Santa Lucia Range. One of the most significant advantages of the chosen site was the nearly complete lack of potentially interfering sources such as industry or vehicular traffic. There are no major freeways in the area and little or no traffic during the evenings and nighttime. The largest road, Highway 1, is one lane each way and serves only local truck traffic. There are no major $\mathrm{PM}_{2.5}$ producing local industries. The nearest major cities are Monterey (population 410,000) approximately 80 miles north-west, San Luis Obispo (population 270,000) approximately 30 miles south-east, and Paso Robles (population 28,000) approximately 20 miles east. Due to the distance, topography, prevailing meteorology, and relatively good air quality in these nearby regions, transport of pollutants does not significantly impact air quality in Cambria. Although Cambria does not have other significant pollutant sources, residential wood burning is common. Because of the age of the neighborhoods and the characteristics of the homes, a large percentage of the homes in Cambria have fireplaces and/or woodstoves. In addition, the close proximity to available wood results in many homes using wood for all or a significant portion of their heating needs.

The field study consisted of 15 intensive operation periods (IOP) over the course of two winter seasons (2009 and 2010). IOP nights were chosen based on favorable meteorological forecasts. Ideal IOP weather included a combination of low temperatures (to encourage wood burning), moderate to low wind speeds (to reduce dispersion), inversions (to reduce vertical dispersion), and dry weather (to eliminate precipitation scavenging and prevent filter moisture).

Filter samples were collected using SKC Inc. Model 200 Personal Environmental Monitors (PEMs) with $\mathrm{PM}_{2.5}$ size selection and Leland Legacy flow-controlled pumps (SKC Inc.). A mask containing a $2 \mathrm{~cm}$ opening was used to decrease the deposit area and thus increase measurement sensitivity. For each IOP, all pumps were programmed to run for 12 hours either between 6 p.m. and 6 a.m. or 5 p.m. and 5 a.m., depending on when sunset occurred. The twelve hour sampling period was chosen to coincide with the hours where wood burning is most prevalent and exclude daytime hours where burning is not prevalent and other aerosol sources are more dominant. PEMs and aethalometers were distributed as evenly as possible over the study area. Sampling locations were restricted to volunteers' homes and locations where the PEMs would be less likely disturbed. In general, sampler locations were kept relatively consistent. However access and logistical constraints led to some variation in sampler placement.

Filter samples were analyzed using a light transmission method to characterize the spectral light absorption by aerosol samples collected on quartz fiber filters. Transmission was measured using a custom built optical spectrometer that allowed placement of filter samples between the light source and detector. The light source was a 
lamp with an emission spectrum extending from the near ultraviolet to the near infrared and the spectrometer was equipped with a fixed diffraction grating and a linear CCD-array detector. Light attenuation (ATN) was calculated from measured sample light transmission $(\mathrm{T})$ : ATN $=100 \ln (1 / \mathrm{T})$. In this study, $\mathrm{T}$ was defined as $\left(\mathrm{I}_{\mathrm{s}} / \mathrm{I}_{\mathrm{s}, \mathrm{o}}\right) \times\left(\mathrm{I}_{\mathrm{r}, \mathrm{o}} / \mathrm{I}_{\mathrm{r}}\right)$, where $\mathrm{I}_{\mathrm{s}}$ and $\mathrm{I}_{\mathrm{s}, \mathrm{o}}$ are the measured intensities of light transmitted through a quartz filter sample prior to and after removal of carbonaceous material by heating to $800^{\circ} \mathrm{C}$ in oxygen, $\mathrm{I}_{\mathrm{r}}$ and $\mathrm{I}_{\mathrm{r}, \mathrm{o}}$ are the intensities of light transmitted through a reference quartz filter measured at the same time as $I_{s}$ and $I_{s, 0}$, respectively. Measurements of $\mathrm{I}_{\mathrm{s}}$ and $\mathrm{I}_{\mathrm{s}, \mathrm{o}}$ were made using the same quartz filter.

The amount of light absorbed by particulate matter generally increases with decreasing wavelength, and a power law relationship is often used to express the spectral selectivity: ATN $=\mathrm{K} \cdot \lambda^{-\mathrm{AAE}}$, where ATN is the spectrally dependent light attenuation measured, $\mathrm{K}$ is a constant, $\lambda$ is the wavelength of light transmitted through particulate matter samples, and AAE is the absorption Ångström exponent. The value of the AAE is indicative of the source of the particulate matter. For example, the AAE of motor vehicle exhaust is $\sim 1$, whereas biomass burning smoke exhibits stronger absorption selectivity with AAE 2 [12]-[14]. For example, it has been shown that smoldering combustion of pine needles produces soluble particles (i.e., not BC) that exhibit a strong absorption spectral dependence [15]. The increased spectral selectivity is directly related to the presence of lightabsorbing organic carbon in the sample. By extracting from a biomass smoke sample a large portion of the OC, Kirchstetter et al. [12] found that AAE decreased from 2.2 to 1.3. In contrast, removal of OC from motor vehicle particulate matter had a negligible effect on the AAE.

Spectral analysis indicated that wood smoke was the dominant particle source and that black carbon concentration performed as well as any of the other surrogate measurements of wood smoke particle concentration [16]. As a result, the analysis of the variability of wood smoke concentrations within the study area was performed using black carbon (BC) concentrations to represent the amount of wood smoke at the sampling locations. Twelve-hour average black carbon concentrations were determined by dividing the measured ATN at $880 \mathrm{~nm}$ on quartz filter samples by $16.6 \mathrm{~m}^{2} / \mathrm{g}$. This method is consistent with the attenuation coefficient and calculation of black carbon concentrations in aethalometers.

BC measurements were also performed using Magee Scientific aethalometers at 1- or 2-minute time resolution. Of the four different aethalometers used in this study, one was multi-wavelength, measuring light attenuation at 370, 470, 520, 590, 660, 880, and $950 \mathrm{~nm}$ and three were dual wavelength, measuring light attenuation at 370 and $880 \mathrm{~nm}$. Aethalometers were co-located with a PEM and placed outside of the homes of volunteers in locations where they would not be disturbed and where an outdoor power source was available. For this study, the aethalometers were simultaneously run side-by-side over a period of 24 hours and their internal calibration values, $\sigma_{\mathrm{sG}}$, were adjusted to more precisely represent one another. Values below the lower detection limit (LDL) were replaced by the LDL of 1 ng noise per 20 liters air flow [17] during data analysis.

Local weather stations deployed by other entities (weather underground and fire department stations) were used to collect the needed meteorological data. In addition, two meteorological instruments were deployed for some of the IOPs during this study. An EBAM weather station (Met One Instruments, Inc., wind combination sensor Model 034B) was deployed during IOPs 4b through 10b and an ultrasonic anemometer (Young Model 81,000 ) was deployed during IOPs $8 \mathrm{~b}$ through $10 \mathrm{~b}$.

The identification of wood burning sources was conducted using a Fluke Ti25 Thermal Imager. The Fluke Ti25 can measure the temperature of objects ranging from $-4^{\circ} \mathrm{F}$ to $662^{\circ} \mathrm{F}$ within accuracy of $\pm 2^{\circ} \mathrm{C}$ or $2 \%$ and capture thermal images. To identify wood burning sources, the Fluke Ti25 was used to determine chimney temperature. Chimney temperatures detected above $75^{\circ} \mathrm{F}$ were considered to be burning wood and images of burning sources were captured.

Table 1 summarizes sampling period date and time, number of PEMs and aethalometers deployed, and meteorological instruments used.

\section{Results and Discussion}

Wood smoke variability was analyzed through variability in black carbon concentrations. Although several different methods have been used as a surrogate for wood smoke, including levoglucosan, organic carbon, and black carbon, for this study black carbon was found to be as accurate as any other marker for wood smoke concentration. The lack of other sources of nighttime particulate matter aided in allowing black carbon to serve as an acceptable surrogate for wood smoke. 
Table 1. Summary of sampling times, instruments deployment, and conditions during Intensive Operational Periods (IOPs) for the field study conducted in Cambria, CA.

\begin{tabular}{|c|c|c|c|c|c|c|}
\hline IOP & Start Date & Start Time & \# PEMs & \# Aeths & $\begin{array}{c}\text { Average } \\
\text { Wind Speed }^{* *}(\mathrm{mph})\end{array}$ & $\begin{array}{c}\text { Average Wind } \\
\text { Direction }^{* *} \text { (degrees) }\end{array}$ \\
\hline \multicolumn{7}{|c|}{ Winter 2009} \\
\hline $1 \mathrm{a}$ & Jan 31 & $18: 00$ & 9 & 2 & 1.7 & 250 \\
\hline $2 \mathrm{a}$ & Feb 18 & $18: 00$ & 11 & 2 & 2.0 & 130 \\
\hline За & Feb 26 & $18: 00$ & 8 & 1 & 2.2 & 120 \\
\hline $4 \mathrm{a}$ & Feb 27 & $18: 00$ & 11 & 2 & 1.2 & 350 \\
\hline $7 \mathrm{a}^{*}$ & Mar 15 & 18:00 & 12 & 1 & 8.4 & 90 \\
\hline $8 a^{*}$ & Mar 20 & 18:00 & 12 & 2 & 3.0 & 90 \\
\hline \multicolumn{7}{|c|}{ Winter 2010} \\
\hline $2 b$ & Jan 23 & 18:00 & 11 & 3 & 2.5 & 240 \\
\hline $3 b$ & Jan 30 & $18: 00$ & 16 & 3 & 1.3 & 300 \\
\hline $4 \mathrm{~b}$ & Feb 13 & $17: 00$ & 15 & 3 & 0.8 & 290 \\
\hline $5 b$ & Feb 28 & $17: 00$ & 15 & 4 & 1.8 & 20 \\
\hline $6 \mathrm{~b}$ & Mar 4 & $17: 00$ & 14 & 4 & 2.4 & 340 \\
\hline $7 \mathrm{~b}$ & Mar 11 & $17: 00$ & 15 & 4 & 1.8 & 170 \\
\hline $8 b$ & Mar 15 & 18:00 & 15 & 4 & 2.8 & 280 \\
\hline $9 b$ & Apr 3 & 18:00 & 15 & 4 & 2.6 & 230 \\
\hline $10 \mathrm{~b}$ & Apr 23 & $18: 00$ & 15 & 3 & 1.7 & 110 \\
\hline
\end{tabular}

${ }^{*}$ These IOPs were excluded in most results and analyses due to a high prevalence of PEM BC concentrations lower than the detection limit. ${ }^{* *}$ Based on meteorological data from the Lodge Hill Community Service Fire District station averaged over the 12-hour sampling period.

The variability of wood smoke concentration was considered both in terms of variability with time at a given location and variability with location within the study area. In addition the variability of meteorological data is presented to aid with the interpretation of the concentration results. Two metrics for variability were used. The first was the standard deviation about a mean concentration and the second was the range of concentrations measured. Both metrics were used for investigating both temporal and spatial distributions.

\subsection{Variability of Meteorological Data}

Meteorological stations are typically used to represent regions of many square miles, however wind speed and direction near the surface can vary substantially over shorter distances depending on terrain and obstructions. Due to the low stack heights, prevalence of inversions, and short distances between sources and receptors in this study, local meteorology variability is expected to be a significant factor in dispersion.

In addition to the equipment deployed for this study, Cambria weather data was available through the Weather Underground website which provides free historical and real-time weather data in both national and international locations. Two Weather Underground PWS stations located southeast of the study site were used, one in the Marine Terrace neighborhood and one in the Lodge Hill neighborhood. The Marine Terrace station is located about 2 miles from the study area on the roof a home located in a residential neighborhood close to the coast. The Lodge Hill station is located at the Cambria Community Services District Fire Department (LH CSDF) that is 1.8 miles from the study site on a tower, approximately 25 feet above the ground. The elevations for the Marine Terrace and LH CSDF stations are 53 and $260 \mathrm{ft}$, respectively, and meteorological readings are recorded every 10 minutes and every 30 minutes for Marine Terrace and LH CSDF, respectively. Figure 1 provides a map of the meteorological stations in relation to the study area.

Despite the relatively short distances between the meteorological stations, significant differences were found between them. As shown in Figure 2 the Marine Terrace (MT) station wind speeds on average were almost 


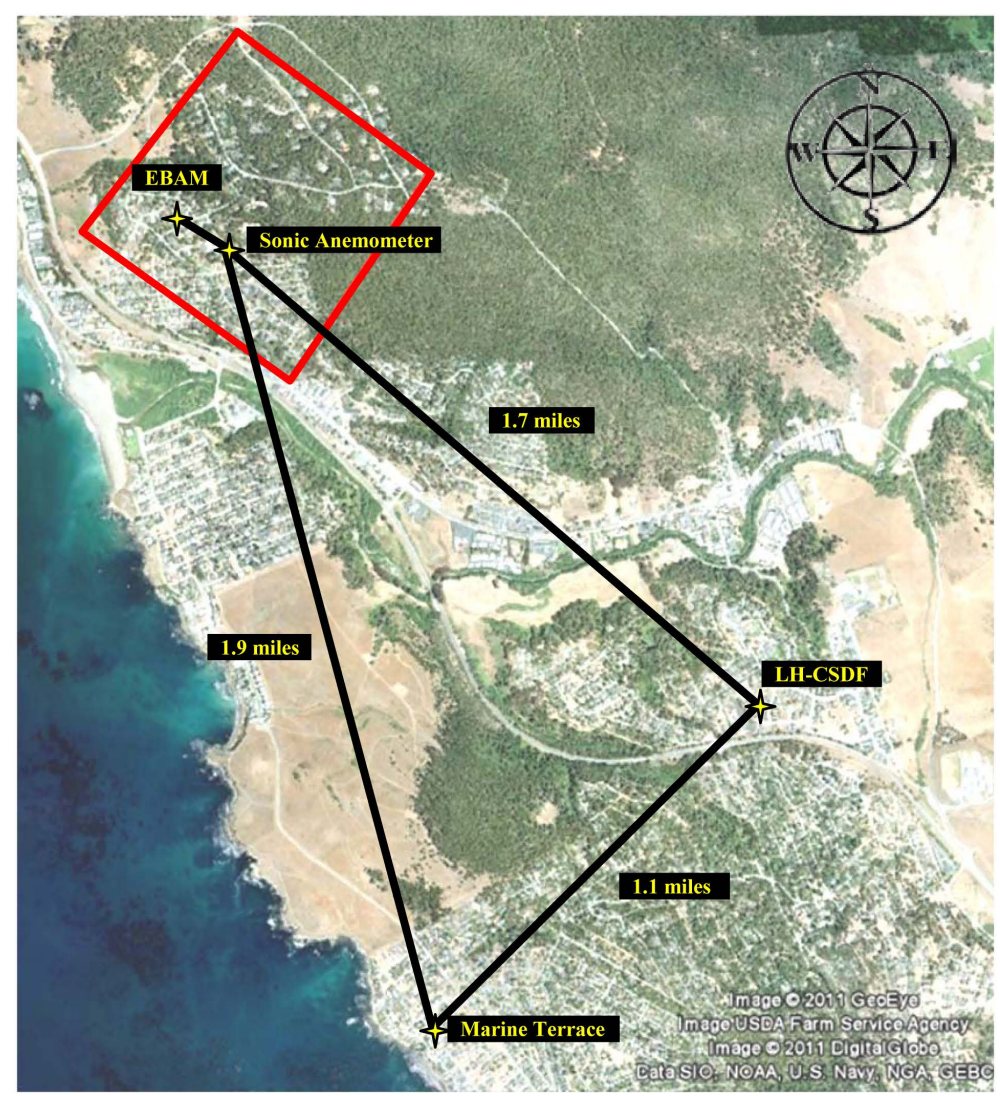

Figure 1. Map of meteorological stations in Cambria, CA area relative to the study area, as shown by the box in the northern portion of the map.

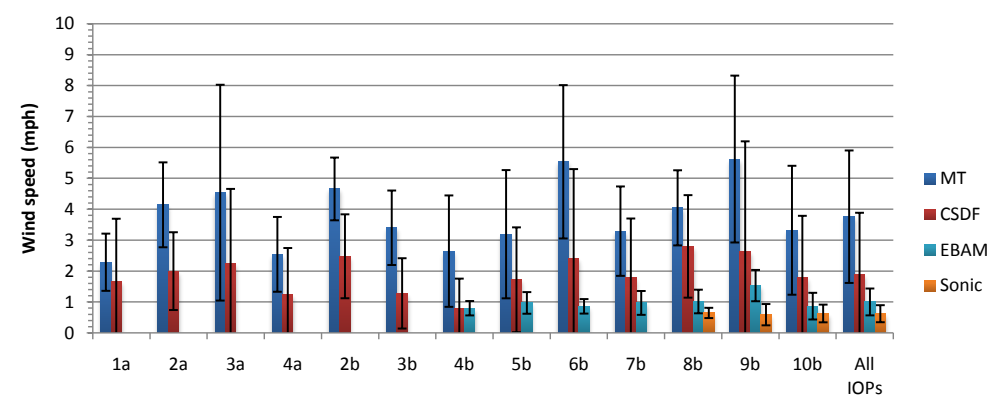

IOP

Figure 2. Averages and standard deviations for wind speed during each Intensive Operational Period (IOP) for the stations shown in Figure 1.

twice as high as LH CSDF wind speeds, and more than three times as high as Sonic and EBAM stations. The lower EBAM and Sonic wind speeds are likely due to their placement closer to ground level (approximately breathing height). On average over stations, wind direction did not vary as widely for the MT, LH CSDF, and EBAM stations, but the Sonic station on average originated from the opposite direction with the exception of one case. Observing each IOP's dominant wind direction, for almost all cases, dominant wind directions for each station were not greater than 90 degrees away the dominant wind directions of other stations. Figure 2 summarizes wind speed variability for all stations over each IOP. Temperature, with measurements available at all stations but LHCSDF, was fairly consistent over all locations, varying about $\pm 5^{\circ} \mathrm{F}$ over all IOPs. The LH CSDF station was expected to be most representative of the study area among available local stations due to its similarity to the study area in topography, terrain, and proximity to the ocean. 


\subsection{Temporal and Spatial Variability of Real Time Measurements}

Time dependent BC variability was determined for each IOP using 30-minute averaged aethalometer readings. Table 2 details the average, median, and standard deviation for these BC concentrations over each IOP. In general, the variability within IOPs increased when average black carbon concentrations were elevated and decreased at lower concentrations. The temporal and spatial variability is shown in the aethalometer BC concentrations versus time graph for IOP 7b (Figure 3) for the 5 different aethalometer locations labeled A through $\mathrm{E}$ in Figure 4. This graph indicates that at each location there was a significant temporal variation in concentration

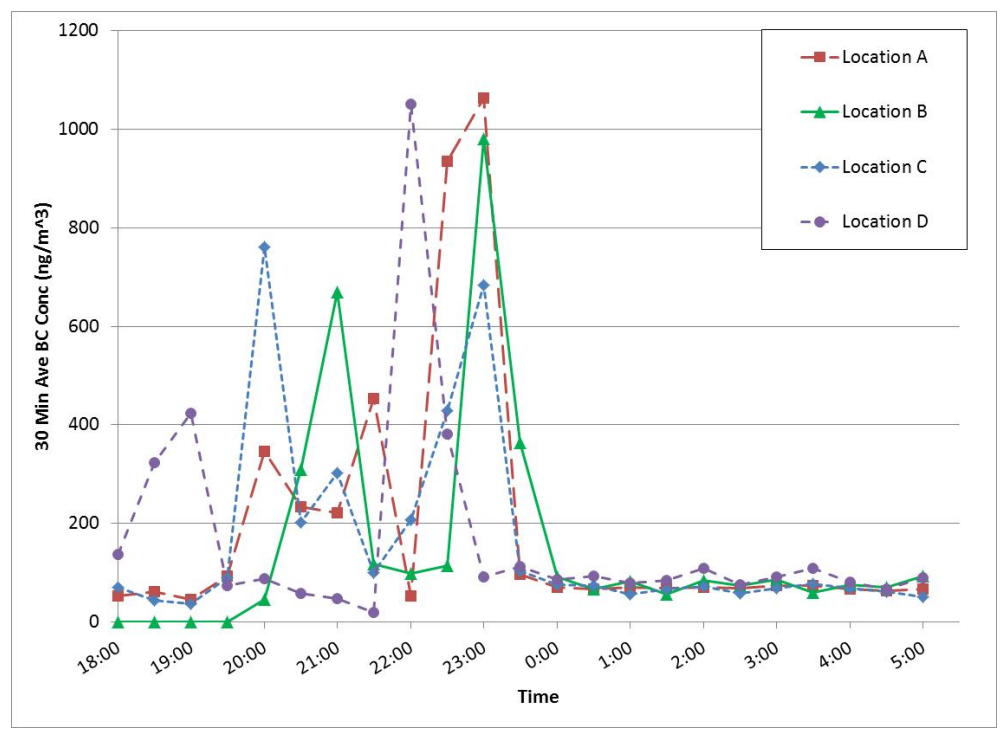

Figure 3. 30 minute average aethalometer black carbon concentrations at 4 locations within the study area, as shown in Figure 4, during IOP 6b (3/4/10 to $3 / 5 / 10)$.

Table 2. Aethalometer black carbon (BC) concentrations, averages, and variability for 12 hour sampling periods over thirteen Intensive Operational Periods (IOPs) conducted in Cambria, CA during the winters of 2009 and 2010. Statistics are based on 30 min averaged BC concentrations measured during each IOP.

\begin{tabular}{|c|c|c|c|c|c|c|}
\hline IOP \# & $\begin{array}{c}\text { Number of Aethalometers in } \\
\text { Operation }\end{array}$ & $\begin{array}{l}\text { Average } \\
\left(\mathrm{ng} / \mathrm{m}^{3}\right)\end{array}$ & $\begin{array}{l}\text { Median } \\
\left(\mathrm{ng} / \mathbf{m}^{3}\right)\end{array}$ & $\operatorname{Max}\left(\mathbf{n g} / \mathbf{m}^{3}\right)$ & $\operatorname{Min}\left(n g / m^{3}\right)$ & $\begin{array}{c}\text { Standard Deviation } \\
\left(\mathbf{n g} / \mathrm{m}^{3}\right)\end{array}$ \\
\hline $1 \mathrm{a}$ & 2 & 385 & 359 & 902 & 238 & 132 \\
\hline $2 \mathrm{a}$ & 2 & 110 & 69 & 397 & 32 & 88 \\
\hline 3a & 1 & 54 & 32 & 139 & 14 & 42 \\
\hline $4 a$ & 2 & 137 & 99 & 883 & 7 & 191 \\
\hline $2 \mathrm{~b}$ & 3 & 141 & 125 & 298 & 77 & 47 \\
\hline $3 b$ & 3 & 184 & 91 & 1060 & 4 & 245 \\
\hline $4 \mathrm{~b}$ & 3 & 626 & 237 & 16720 & 13 & 1996 \\
\hline $5 b$ & 4 & 511 & 194 & 18160 & 7 & 1843 \\
\hline $6 \mathrm{~b}$ & 4 & 167 & 77 & 1063 & 7 & 227 \\
\hline $7 \mathrm{~b}$ & 4 & 151 & 131 & 896 & 4 & 99 \\
\hline $8 b$ & 4 & 141 & 82 & 2006 & 7 & 252 \\
\hline $9 \mathrm{~b}$ & 4 & 192 & 100 & 4134 & 4 & 461 \\
\hline $10 \mathrm{~b}$ & 3 & 144 & 123 & 553 & 87 & 62 \\
\hline \multicolumn{2}{|r|}{ Average } & 226 & 132 & 3630 & 38 & 438 \\
\hline
\end{tabular}




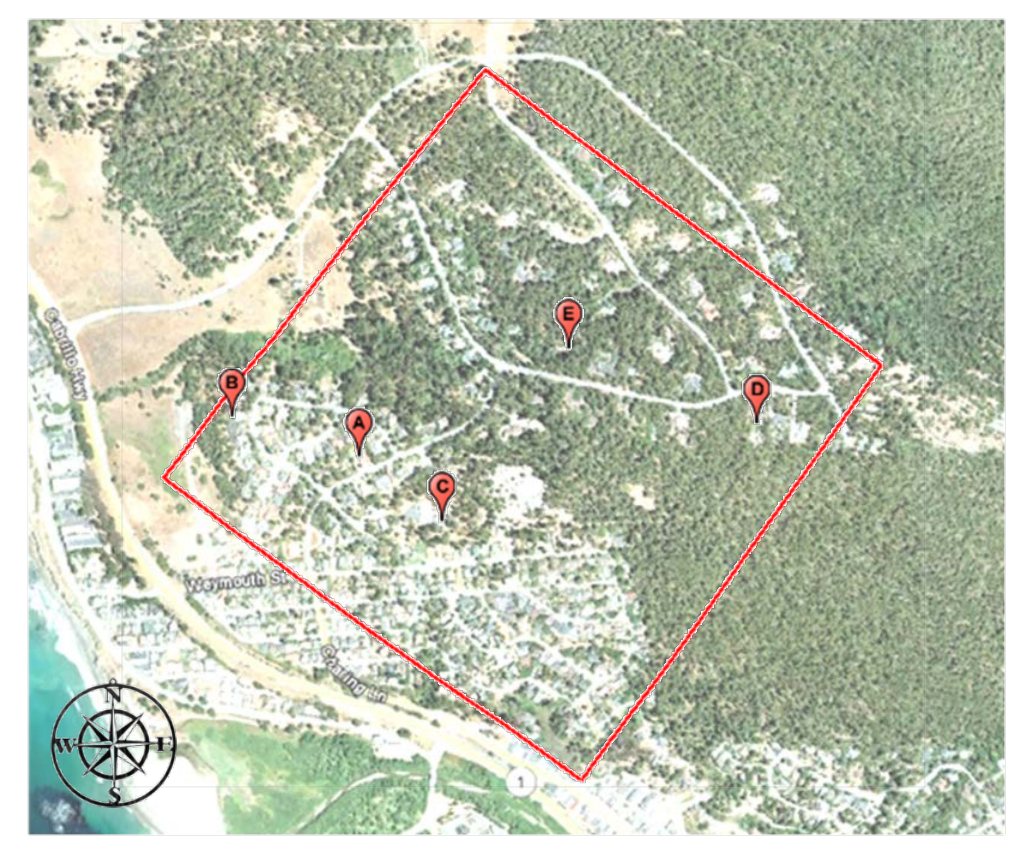

Figure 4. Aethalometer sampling locations used during the Intensive Operational Periods (IOPs). Note: Aethalometers were not deployed at all locations during every IOP.

and a significant spatial variation during the early evening hours when concentrations were higher. Comparison of IOPs $5 b$ through $9 \mathrm{~b}$, all containing the same number of aethalometers, in Table 2, indicates that although the number of aethalometers in operation may affect the magnitude of the standard deviation, since averaging BC at more sites increases the spatial variability captured by the statistic, it is not the dominant consideration. Spatial variability likely accounts for a smaller portion of the standard deviation than temporal variability, because typical differences in $\mathrm{BC}$ concentration between locations are much smaller than the differences between the highest and lowest BC concentrations measured at a single location. This effect was also been seen when analyzing the data collected every minute. For one minute BC concentrations over all IOPs the standard deviation was much larger, $2640 \mathrm{ng} / \mathrm{m}^{3}$, than for the 30 minute data, $438 \mathrm{ng} / \mathrm{m}^{3}$. The high standard deviation in the data is likely the result of turbulent fluctuations when the source is near the receptor, but also includes the effect of higher measurement noise in the one minute readings.

Spatial variability based on location within the study area was also investigated based on aethalometer data at the five locations shown in Figure 4. Median, range, and quartiles by sampling site across all IOPs are displayed in Figure 5 based on aethalometer black carbon measurements averaged over 30 minutes. The highest BC average and standard deviation were observed at site B where the highest BC concentrations were also detected. However, the median at B was similar to the medians at other sites. This difference is due to the fact that the average for site B is highly influenced by data from IOPs $4 \mathrm{~b}$ and $5 \mathrm{~b}$ when a home adjacent to the site was burning and influence from this source created very high concentrations. The average and median concentration for sites A, C, and D were fairly similar, while the median concentration at site E was lower. Standard deviations were also fairly similar with the clear exception of site B and a slightly higher standard deviation for site A.

\subsection{Spatial Variability of Integrated (Filter) BC Measurements}

Although aethalometer measurements provided both spatial and temporal variability, their limited number significantly restricted the number of locations that could be measured simultaneously. To obtain values for a larger number of locations simultaneously during each IOP, between 8 and 16 Personal Environmental Monitors (SKC, $2.5 \mu \mathrm{m}$ PEMs) successfully collected 12 hour outdoor filter samples within the study area. These filters were subsequently analyzed using light attenuation and the results were used to determine black carbon (BC) concentration, as well AAE values. Figure 6 shows all of the PEM sampling locations used during the study. Not all sites were used for all IOPs. Although PEM locations were kept as consistent as possible between IOPs, location 

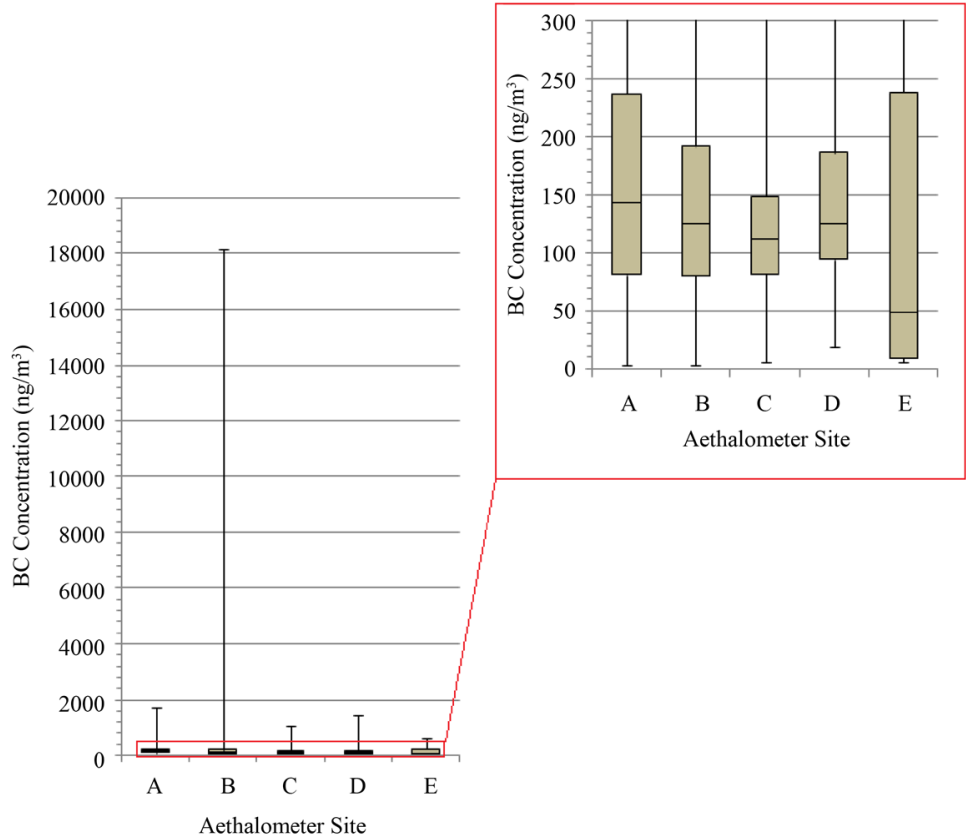

Figure 5. Box plot comparing aethalometer black carbon (BC) concentrations between sites, as shown in Figure 4, over all IOPs. Note: Aethalometers were not deployed at all locations during every IOP Boxes denote the $1^{\text {st }}$ and $3^{\text {rd }}$ quartile and median value for all concentrations. The whiskers indicate the maximum and minimum values.

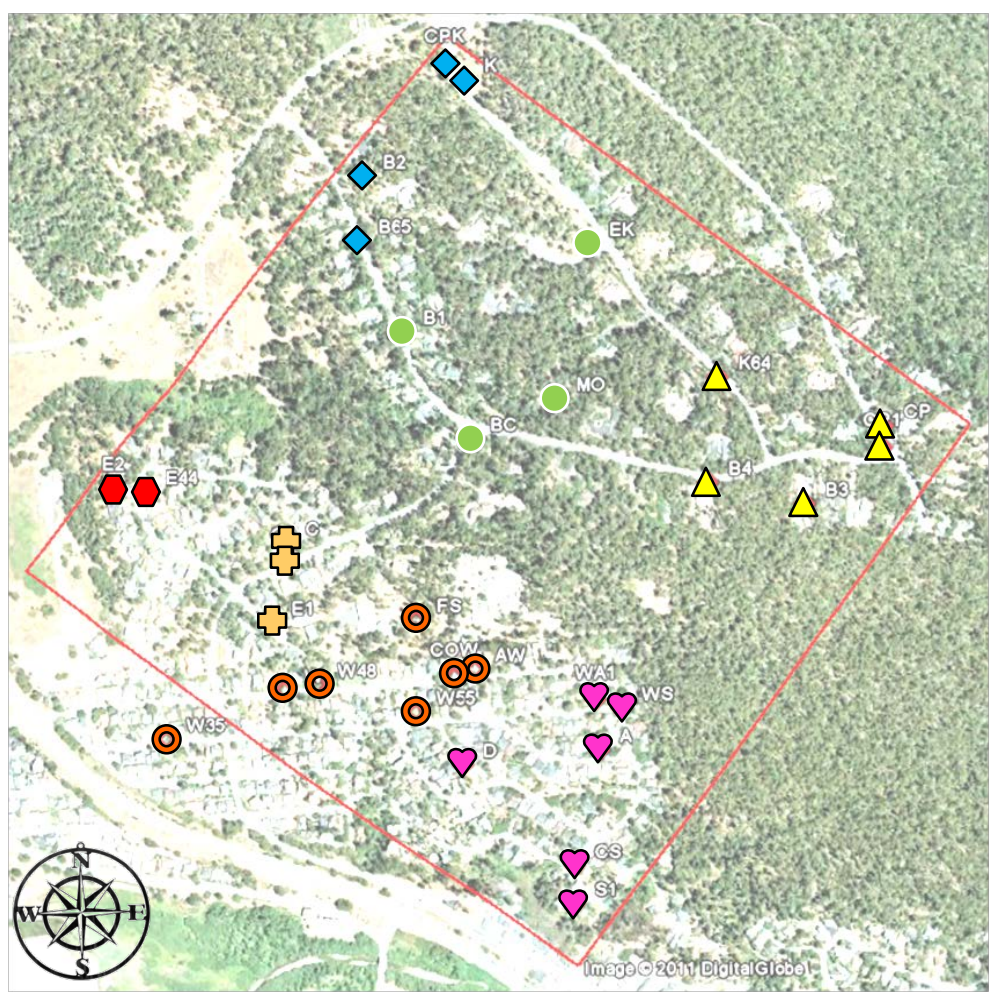

Figure 6. Labels for all PEM sample locations used during the study. Only a subset of these locations was used for each Intensive Operational Period (IOP). Location symbols are coded to assist with grouping of results. 
changes occurred between sampling seasons and sites sometimes shifted due to access issues.

The average PEM BC concentration over all locations and IOPs was $221 \mathrm{ng} / \mathrm{m}^{3}$ with a standard deviation of $174 \mathrm{ng} / \mathrm{m}^{3}$. IOPs 7a and 8a were excluded from most analyses due to the high number of samples below the detection limit. The low concentrations during these runs are attributed to higher wind speeds and wind gust speeds during the early evening when sources were active and the lack of an inversion during IOP 8a. Table 3 summarizes PEM BC averages, medians, and standard deviations by IOP. Figure 7 shows box plots for each

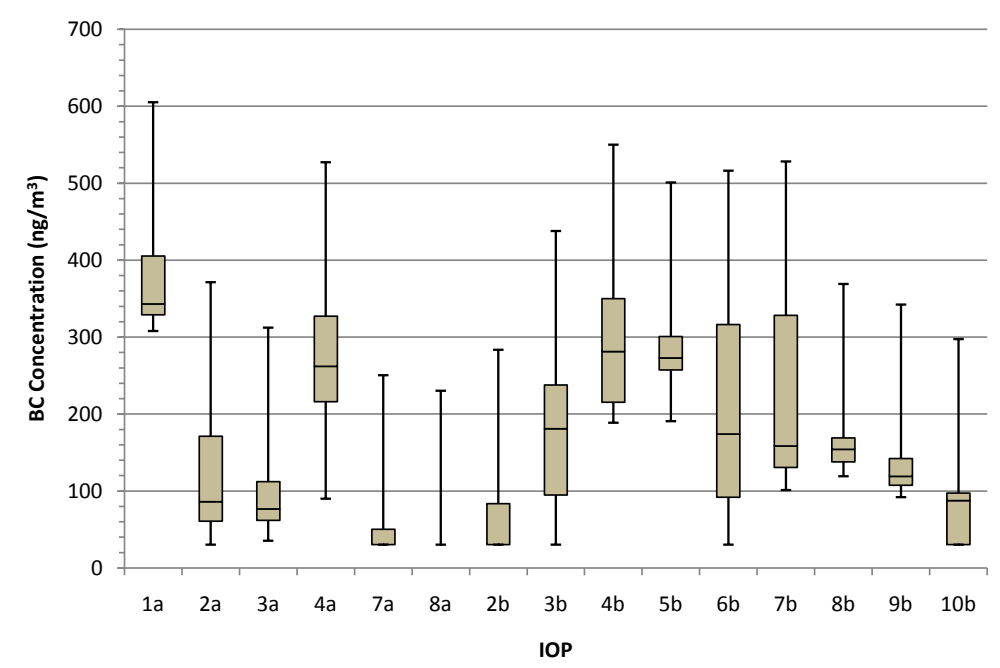

Figure 7. Box plots showing black carbon concentrations for 12 hour PEM filter samples by Intensive Operational Period (IOP). Box plots denote $1^{\text {st }}$ quartile, median, and $3^{\text {rd }}$ quartile values. The whiskers indicate the maximum and minimum values.

Table 3. Black carbon concentrations for 12-hour PEM filters averaged by Intensive Operational Period (IOP).

\begin{tabular}{|c|c|c|c|c|c|}
\hline IOP & $\begin{array}{c}\text { Number of PEMs in } \\
\text { Operation }\end{array}$ & $\begin{array}{c}\text { Number of Sources } \\
\text { Detected }\end{array}$ & Average (ng/m $\left.\mathbf{m}^{3}\right)$ & Median (ng/m $\left.\mathbf{m}^{3}\right)$ & $\begin{array}{l}\text { Standard } \\
\text { Deviation }\end{array}$ \\
\hline $1 \mathrm{a}$ & 9 & 5 & 371 & 343 & 60 \\
\hline $2 \mathrm{a}$ & 11 & 7 & 165 & 86 & 223 \\
\hline 3а & 8 & 5 & 82 & 76 & 32 \\
\hline $4 a$ & 11 & 9 & 308 & 262 & 185 \\
\hline $7 a^{*}$ & 16 & 11 & 60 & 30 & 36 \\
\hline $8 a^{*}$ & 12 & 10 & 33 & 30 & 6.7 \\
\hline $2 \mathrm{~b}$ & 11 & 18 & 82 & 30 & 86 \\
\hline $3 b$ & 16 & 15 & 203 & 181 & 168 \\
\hline $4 b$ & 15 & 7 & 330 & 281 & 214 \\
\hline $5 b$ & 15 & 8 & 441 & 273 & 651 \\
\hline $6 b$ & 14 & 10 & 220 & 174 & 183 \\
\hline $7 \mathrm{~b}$ & 15 & 14 & 272 & 159 & 251 \\
\hline $8 b$ & 15 & 7 & 187 & 154 & 111 \\
\hline $9 b$ & 15 & 5 & 136 & 119 & 48 \\
\hline $10 \mathrm{~b}$ & 15 & 12 & 81 & 88 & 47 \\
\hline \multicolumn{3}{|c|}{ Average $^{* *}$} & 221 & 171 & 174 \\
\hline
\end{tabular}

${ }^{*}$ These IOPs were not included in analyses due to a high prevalence of PEM BC concentrations lower than the detection limit. ${ }^{* *}$ Average concentrations listed in this table assume values lower than the detection limit to be the average of a zero concentration and the detection limit $\left(60.5\right.$ ng/m ${ }^{3}$ ), or $30.2 \mathrm{ng} / \mathrm{m}^{3}$. 
IOP showing the variability in concentrations between nights. The large range of concentrations within a single IOP illustrates that PEM concentrations tended to vary widely between sites with most concentrations much lower than the maximum concentrations for each IOP.

Although there was a high degree of concentration variability between sites, there was also a general tendency for some sites to have higher concentrations than others. In addition to general variability, a small subset of samples exhibited concentrations that were much higher than any other samples during that IOP. It is expected that these very high concentrations were strongly influenced by a single nearby source impinging onto the sampler. A general concentration trend can be seen more clearly when concentrations for all IOPs are averaged by site (Figure 8). In general, samples taken nearer the northeastern edge of the study area tended to have lower concentrations than those in the southwestern portion of the study area. There are several topographic differences between the two areas which could contribute to the observed differences. For instance, the northeastern portion has more tree coverage, lower housing/source density, and a higher elevation than the southwestern area. A potentially more important factor is that the winds most often entered the study area from the north or east during the IOPs. Consequently, black carbon from sources within the study area would be expected to increase in concentration within the air mass as the relatively clean entering air encountered sources within the study area. This gradient in concentration was apparent in several of the IOPs, such as IOP $3 \mathrm{~b}$ shown in Figure 9. However, this trend was not always consistent and for some IOPs, such as IOP 1a shown in Figure 10, there was no concentration gradient. For the 15 IOPs in this study, six showed a concentration gradient with concentrations generally increasing for locations toward the southwestern portion of the study area, three showed a slight but inconsistent concentration gradient, four showed no perceptible concentration pattern, and two had concentrations too low to determine if a pattern existed.

\section{Conclusions}

A combination of filter and aethalometer measurements provided both temporal resolution and relatively high spatial resolution for a $1 \mathrm{~km}^{2}$ residential area with multiple burning sources within the neighborhood. Aethalometer data showed that concentrations varied both temporally and spatially, especially during the evening hours when burning was most active. Standard deviations for 30 minute concentrations were typically near or above the average concentrations measured and the maximum recorded 30 minute average concentration was over 35 times higher than the average of all concentrations for that IOP. Both filter and aethalometer results indicated a high level of spatial concentration variability during some but not all IOPs. The highest 12-hour PEM concentration

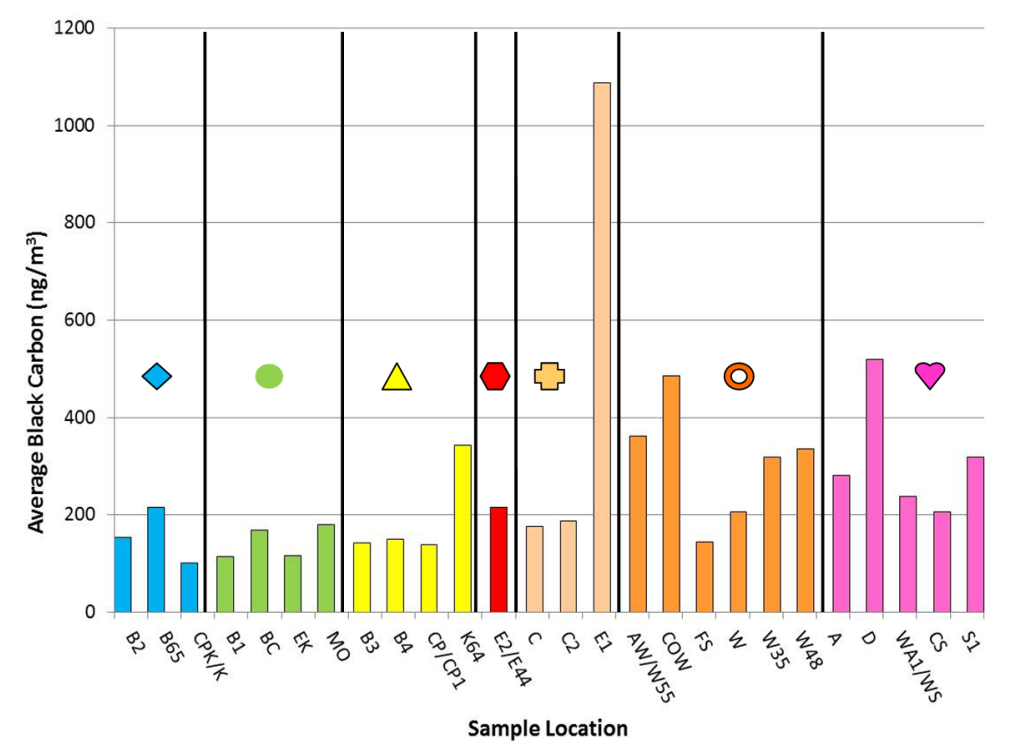

Figure 8. Average 12-hour PEM filter black carbon concentration averaged by sampling location for all IOPs. Section symbols match markers on Figure 6. Note: IOPs 7a and 8a were excluded due to a high number of samples below the detection limit. Not all sites were used for all IOPs. 


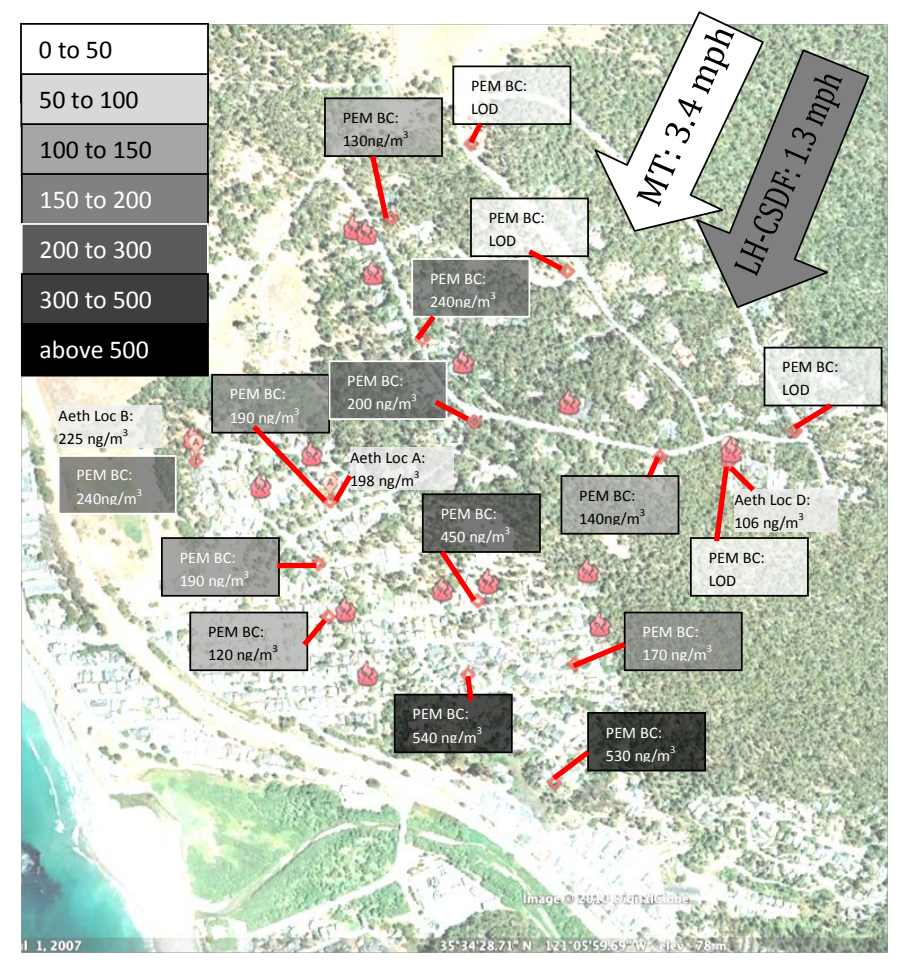

Figure 9. 12-hour PEM filter and 12-hour average aethalometer black carbon PEM 2.5 concentrations (ng/m ${ }^{3}$ ) for IOP 3b collected from 6 pm 1/30/10 to 6 am 1/31/10. Results have been shaded by concentration, using the schematic in the upper left, to aid in visualization. Arrows represent average wind speeds and directions for two local meteorological stations. Flame icon denotes location of a detected burning source.

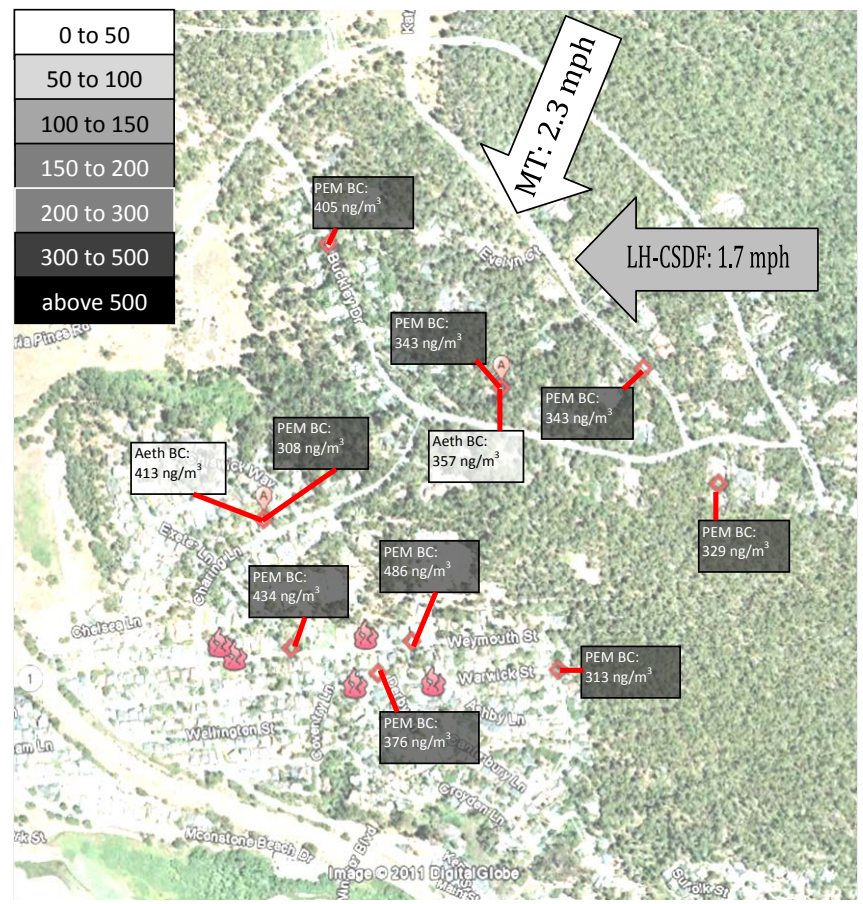

Figure 10. 12-hour PEM filter and 12-hour average aethalometer black carbon PEM 2.5 concentrations (ng/m ${ }^{3}$ ) for IOP $1 \mathrm{a}$ collected from 6 pm 1/31/09 to 6 am 2/1/09. Results have been shaded by concentration, using the schematic in the upper left, to aid in visualization. Arrows represent average wind speeds and directions for two local meteorological stations. Flame icon denotes location of a detected burning source. 
was seen at sampler E1 during IOP 5b. The concentration at E1 was more than 10 times higher than average of all of the other PEM concentrations during this IOP, and 6.7 times higher than the next highest PEM. The spatial variability observed was not random, but followed a pattern with certain locations tending to have higher concentrations while others had a tendency for lower concentrations. If the average concentration over all study nights was assumed to represent the neighborhood (such as might be assumed when using a central monitoring site), the concentrations actually experienced over the study period were as much as $300 \%$ higher or $60 \%$ lower, depending on location within the neighborhood. This was most likely due to a combination of meteorological, topographic, and source location variables. Although these variables will almost certainly be different for other regions, it is likely that patterns in meteorology and source locations will yield similar tendencies toward higher and lower concentrations in different sections of neighborhoods. This means that even during periods of relatively good air quality, individuals located near a local source of wood smoke can receive substantial exposures and that average exposures will not be a sufficient indicator of exposures to all individuals within a neighborhood. For sensitive individuals this could lead to health effects even when air quality measurements indicate no risk.

\section{Acknowledgements}

This work was supported by the California Air Resources Board (CARB) under contracts 07-308. The statements and conclusions in this paper are those of the researchers and not necessarily those of CARB. We would like to thank Carrie Esaki and Aristotle Ou for their assistance with the winter 2010 field sampling campaign and the San Luis Obispo County Air Pollution Control District for their loan of equipment and field support.

\section{References}

[1] Gorin, C.A., Collett Jr., J.L. and Herckes, P. (2006) Wood Smoke Contribution to Winter Aerosol in Fresno, CA. Journal of the Air \& Waste Management Association (1995), 56, 1584-1590.

[2] Goswami, E., Larson, T., Lumley, T. and Liu, L.J.S. (2002) Spatial Characteristics of Fine Particulate Matter: Identifying Representative Monitoring Locations in Seattle, Washington. Journal of the Air \& Waste Management Association (1995), 52, 324-333.

[3] Weijers, E.P., Khlystov, A.Y., Kos, G.P.A. and Erisman, J.W. (2004) Variability of Particulate Matter Concentrations along Roads and Motorways Determined by a Moving Measurement Unit. Atmospheric Environment, 38, $2993-3002$. http://dx.doi.org/10.1016/j.atmosenv.2004.02.045

[4] Gulliver, J. and Briggs, D.J. (2004) Personal Exposure to Particulate Air Pollution in Transport Microenvironments. Atmospheric Environment, 38, 1-8. http://dx.doi.org/10.1016/j.atmosenv.2003.09.036

[5] Glasius, M., Ketzela, M., Wahlina, P., Jensena, B., Mønstera, J., Berkowicza, R. and Palmgrena, F. (2006) Impact of Wood Combustion on Particle Levels in a Residential Area in Denmark. Atmospheric Environment, 40, 7115-7124. http://dx.doi.org/10.1016/j.atmosenv.2006.06.047

[6] Robinson, D., Monro, J. and Campbell, E. (2007) Spatial Variability and Population Exposure to PM2.5 Pollution from Woodsmoke in a New South Wales Country Town. Atmospheric Environment, 41, 5464-5478. http://dx.doi.org/10.1016/j.atmosenv.2007.01.059

[7] Smargiassi, A., Brand, A., Fournier, M., Yessier, F., Goudreau, S., Rousseau, J. and Benjamin, M. (2012) A Spatiotemporal Land-Use Regression Model of Winter Fine Particulate Levels in Residential Neighborhoods. Journal of Exposure Science and Environmental Epidemiology, 22, 331-338. http://dx.doi.org/10.1038/jes.2012.26

[8] Branis, M., Koznarová, J. and Domasová, M. (2000) Coal and Wood Burning as Main Cause of Particulate Pollution in a Rural Area: Case Study from the Czech Republic. Journal of Aerosol Science, 31, 889-890. http://dx.doi.org/10.1016/S0021-8502(00)90899-1

[9] Allen, G.A., Miller, P.J., Rector, L.J., Brauer, M. and Su, J.G. (2011) Characterization of Valley Winter Woodsmoke Concentrations in Northern NY Using Highly Time-Resolved Measurements. Aerosol and Air Quality Research, 11, 519-530.

[10] Larson, T., Su, J., Baribeau, A., Setton, E. and Brauer, M. (2007) A Spatial Model of Urban Winter Woodsmoke Concentrations. Environmental Science and Technology, 41, 2429-2436. http://dx.doi.org/10.1021/es0614060

[11] Cambria Chamber of Commerce (2010) Facts about Cambria. http://www.cambriachamber.org/info.php

[12] Kirchstetter, T.W., Novakov, T. and Hobbs, P.V. (2004) Evidence That the Spectral Dependence of Light Absorption by Aerosols Is Affected by Organic Carbon. Journal of Geophysical Research-Atmospheres, 109, D21208. 
[13] Sandradewi, J., Prévôt, A.S.H., Weingartner, E., Schmidhauser, R., Gysel, M. and Baltensperger, U. (2008) A Study of Wood Burning and Traffic Aerosols in an Alpine Valley Using a Multi-Wavelength Aethalometer. Atmospheric Environment, 42, 101-112. http://dx.doi.org/10.1016/j.atmosenv.2007.09.034

[14] Sandradewi, J., Prévôt, A.S., Szidat, S., et al. (2008) Using Aerosol Light Absorption Measurements for the Quantitative Determination of Wood Burning and Traffic Emission Contributions to Particulate Matter. Environmental Science \& Technology, 42, 3316-3323. http://dx.doi.org/10.1021/es702253m

[15] Patterson, E.M. and McMahon, C.K. (1984) Absorption Characteristics of Forest Fire Particulate Matter. Atmospheric Environment, 18, 2541-2551. http://dx.doi.org/10.1016/0004-6981(84)90027-1

[16] Kirchstetter, T.W. and Thatcher, T.L. (2012) Contribution of Organic Carbon to Wood Smoke Particulate Matter Absorption of Solar Radiation. Atmospheric Chemistry and Physics, 12, 6067-6072. http://dx.doi.org/10.5194/acp-12-6067-2012

[17] Hansen, A.D.A. (2005) The Aethalometer, Manual. Magee Scientific Company, Berkeley. 
Scientific Research Publishing (SCIRP) is one of the largest Open Access journal publishers. It is currently publishing more than 200 open access, online, peer-reviewed journals covering a wide range of academic disciplines. SCIRP serves the worldwide academic communities and contributes to the progress and application of science with its publication.

Other selected journals from SCIRP are listed as below. Submit your manuscript to us via either submit@scirp.org or Online Submission Portal.
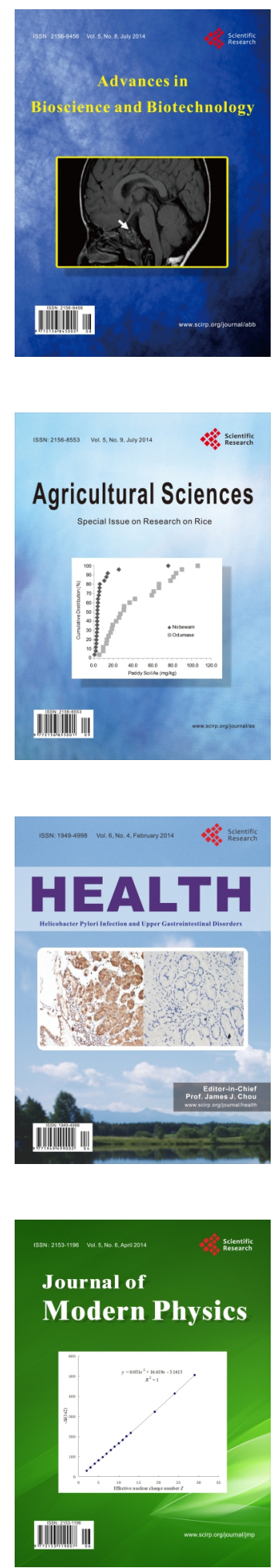
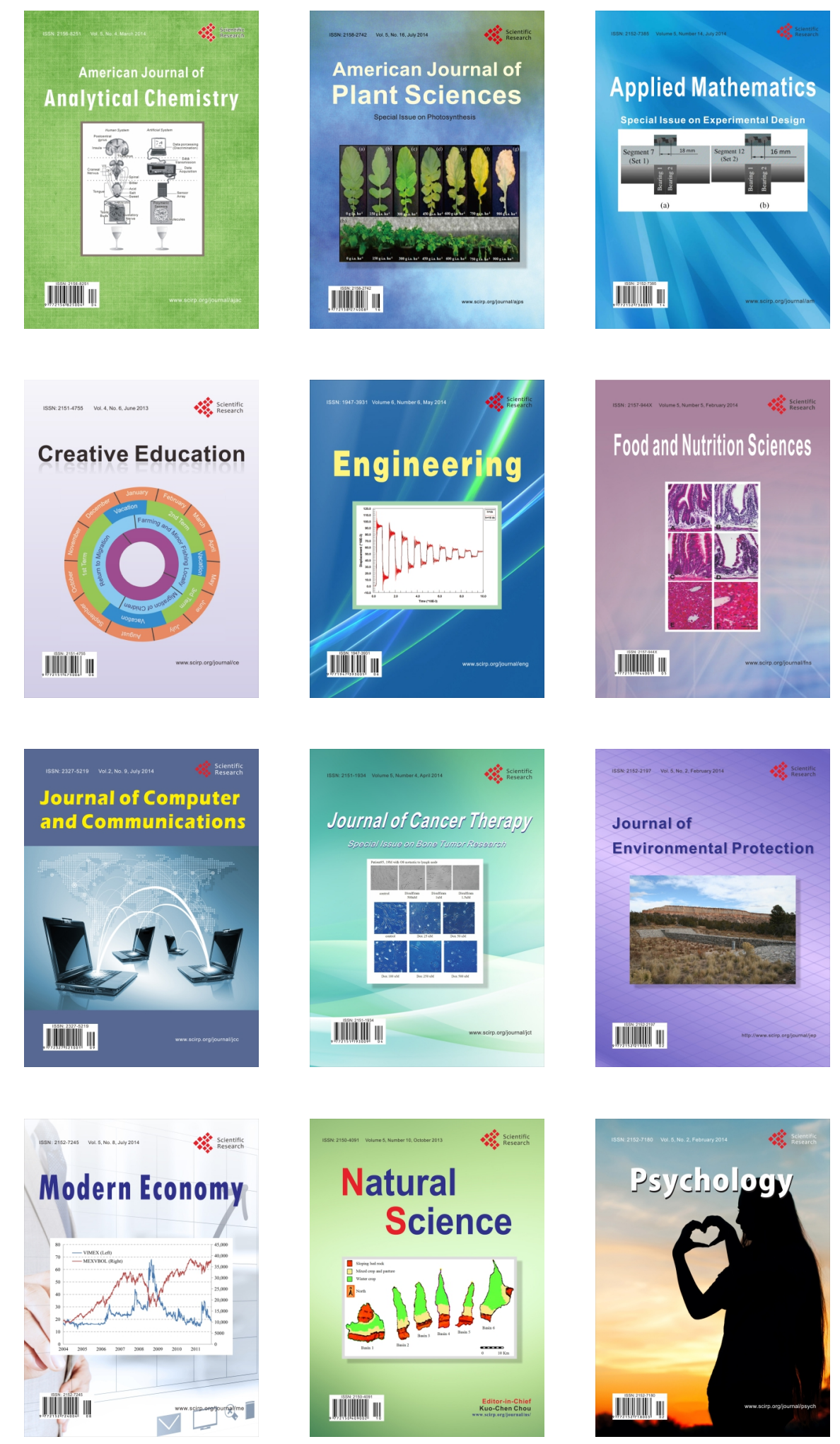